\title{
Radiofrequency electromagnetic field exposure assessment: a pilot study on mobile phone signal strength and transmitted power levels
}

\author{
Christopher Brzozek ${ }^{1,2} \cdot$ Berihun M. Zeleke ${ }^{1,2} \cdot$ Michael J. Abramson ${ }^{1,2} \cdot$ Kurt K. Benke ${ }^{3,4} \cdot$ Geza Benke ${ }^{1,2}$
}

Received: 8 May 2019 / Revised: 22 July 2019 / Accepted: 26 August 2019

(c) The Author(s) 2019. This article is published with open access

\begin{abstract}
In many epidemiological studies mobile phone use has been used as an exposure proxy for radiofrequency electromagnetic field (RF-EMF) exposure. However, RF-EMF exposure assessment from mobile phone use is prone to measurement errors limiting epidemiological research. An often-overlooked aspect is received signal strength levels from base stations and its correlation with mobile phone transmit (Tx) power. The Qualipoc android phone is a tool that provides information on both signal strength and Tx power. The phone produces simultaneous measurements of Received Signal Strength Indicator (RSSI), Reference Signal Received Power (RSRP), Received Signal Code Power (RSCP), and Tx power on the 3G and 4G networks. Measurements taken in the greater Melbourne area found a wide range of signal strength levels. The correlations between multiple signal strength indicators and Tx power were assessed with strong negative correlations found for $3 \mathrm{G}$ and 4G data technologies (3G RSSI -0.93 , RSCP -0.93 ; 4G RSSI -0.85 , RSRP -0.87 ). Variations in Tx power over categorical levels of signal strength were quantified and showed large increases in Tx power as signal level decreased. Future epidemiological studies should control for signal strength or factors influencing signal strength to reduce RF-EMF exposure measurement error.
\end{abstract}

Keywords EMF $\cdot$ Epidemiology $\cdot$ Environmental monitoring

\section{Introduction}

Radiofrequency electromagnetic field (RF-EMF) exposures from mobile (cellular) phones and other RF-EMF emitting devices such as base stations, Wi-Fi routers, laptops, and tablet computers, have become ubiquitous. The steady increase in use of RF-EMF-emitting devices and the new technologies developed have raised concern amongst some sections of the public as well as expert groups [1]. The

Christopher Brzozek

christopher.brzozek@monash.edu

1 Centre for Population Health Research on Electromagnetic Energy (PRESEE), School of Public Health and Preventive Medicine, Monash University, Melbourne, VIC 3004, Australia

2 Department of Epidemiology and Preventive Medicine, School of Public Health and Preventive Medicine, Monash University, Melbourne, VIC 3004, Australia

3 School of Engineering, University of Melbourne, Parkville, VIC, Australia

4 Centre for AgriBioscience, AgriBio, 5 Ring Rd, Bundoora, VIC, Australia
World Health Organization has identified RF-EMF exposure research as a high priority [2]. Yet epidemiological research remains limited by exposure assessment techniques and a scientific consensus on possible health effects remains elusive.

RF-EMF exposure can be categorised as either near field or far field. Near field exposure occurs from RF-EMF devices that emit in close proximity to the body e.g. personal mobile phone use, laptops, tablets, etc. and results in sporadic exposure. Far field exposure from base stations, Wi-Fi routers, FM radio, other mobile phone users, etc. occur from larger distances, resulting in a much lower, but more constant level of RF-EMF exposure. Near field sources are responsible for the bulk of RF-EMF exposure, with personal mobile phone calls responsible for the largest amount of RF-EMF exposure to the brain [3].

Mobile phone use has been used as an exposure proxy in many epidemiological studies [4-10]. These included the INTERPHONE study [11], whose results contributed to an upgrade of RF-EMF exposure to a group 2B possible carcinogen by the International Agency for Research on Cancer (IARC). Yet, mobile phone use is extremely vulnerable to measurement error. For instance, self-reported number of 
calls and the duration of calls have been shown to be inaccurate [12-14]. Although billing records provide more accurate and thorough mobile phone call data, they still lack important information on calls made via over-the-top communication services such as WhatsApp ${ }^{\mathrm{TM}}$, Messenger, Viber ${ }^{\mathrm{TM}}$, and Skype ${ }^{\mathrm{TM}}$.

Also billing records lack data on important variables for RF-EMF exposure assessment, as mobile phone users who make the same number and duration of calls can have vastly different levels of RF-EMF exposure. This includes information on the model of phone used, as different models can have different Specific Absorption Rate (SAR) limits as well as different antennae locations which can vary the level of RF-EMF exposure received [15]. Data on the use of loudspeaker, earphones, and the distance the phone is held from the body is also important, as RF-EMF exposure greatly reduces with the distance the phone is held away from the body. Base station signal strength also greatly affects the amount of RF-EMF exposure, as using a mobile phone in an area of poor signal requires the phone to use more power and increases RF-EMF exposure [15].

In addition to the number and duration of calls, data are required on the transmit ( $\mathrm{Tx}$ ) power from the mobile phone, as well as the distance between the user and the device to accurately assess RF-EMF exposure from mobile phone devices. Previous research on the $2 \mathrm{G}$ data technology Global System for Mobile Communication (GSM) has shown that mobile phone power outputs were on average considerably higher in regional areas that had a low concentration of base stations compared with urban areas $[16,17]$. Similarly for the $3 G$ network, the power output was found to be $\sim 2 \mathrm{~dB}$ higher on average in rural areas compared with urban areas [18]. The output power from mobile phone devices on the $3 \mathrm{G}$ network was also found to be on average lower when compared with the $2 \mathrm{G}$ network [19-21].

The 4G Long Term Evolution (LTE) network has been shown to have a higher 95th percentile time averaged output power level in rural $(6.4 \mathrm{dBm})$ compared with urban $(2.3 \mathrm{dBm})$ and suburban areas $(1.2 \mathrm{dBm})$ [22]. This was again attributed to the larger distance between the mobile phone user and the nearest base station. As distance from the base station has been shown to influence signal strength and RF-EMF exposure [23].

Accurately gathering all these exposure data is extremely difficult, yet important in reducing measurement error. Billing records and mobile phone apps such as XmobiSense have been used to address some of these limitations [24]. However, changes to RF-EMF exposure due to variations in signal strength have been difficult to quantify as personnel exposimeters do not assess the Tx power of a mobile phone. The Qualipoc handheld android (SwissQual, Munich, Germany), is a device developed by engineers for RF optimisation services such as improving the quality of signal or the area coverage of a RF network. This device provides information on both signal strength and Tx power, although it does not include data on the distance the phone is held from the body. It has previously been used in research to verify $3 \mathrm{G}$ and $4 \mathrm{G}$ received power measurements from the android App NetMap [25], as well as other measurement studies [26, 27].

Therefore, first aim of this study was to use the Qualipoc handheld android to assess the correlation between various signal strength indicators and Tx power. The study also aimed to quantify the variations of Tx power for different levels of signal strength across multiple mobile networks in the greater Melbourne area.

\section{Methods}

\section{Study design}

Data were collected between February and March of 2018 in greater Melbourne, Australia. Four participants were recruited via advertisements posted on public notice boards in universities and hospitals across Greater Melbourne. Each participant completed a written consent form and worked within the greater Melbourne area to take part in the study. The Qualipoc enabled mobile phones were given to the four participants to use as they would their regular phones. Participants removed their mobile phone SIM cards from their regular phone and inserted them into the Qualipoc enabled Xperia phone so they were able to maintain their regular phone number and contacts. Participants were given 2-3 days to familiarise themselves with the new phone, add/transfer contacts from their previous phone and download mobile apps they would regularly use.

After that time data were collected across 5 days during standard working hours. Participants were briefed and provided with step by step instructions on how to start and finish the data recording on the mobile phones. At the conclusion of the 5 days, the handsets were returned to the Authors who downloaded the data collected by Qualipoc software directly from the phone for analysis. Data were not collected on the distance of the phone from the body or head. Participants completed a written consent form to take part in the study. The study was approved by the Monash University research ethics committee.

\section{Measurement device}

The Qualipoc handheld android Xperia ${ }^{\mathrm{TM}} \mathrm{XZ}$ model (Sony, Tokyo, Japan) is a smartphone-based tool designed for RF optimisation and mobile network testing which collects objective data on various signal strength indicators as well 
as the Tx power of the mobile device. It has been used in previous mobile phone measurement studies [25-29]. The Qualipoc handsets undergo rigorous 3rd Generation Partnership Project (3GPP), PCS Type Certification Review Board (PTCRB) conformance testing certifications across all the bands supported by the device and are in line with 3GPP specifications. The Qualipoc android collected simultaneous measurements for a number of key performance indicators directly from the handset baseband chipset. These included Received Signal Strength Indicator (RSSI), Reference Signal Received Power (RSRP), and Reference Signal Received Quality (RSRQ) for the 4G network. 'RSSI is a measure of power in a received radio signal. RSRP is a similar measure to RSSI and is the power of the LTE Reference Signals spread over the full bandwidth and narrowband. RSRQ is the ratio of RSRP to RSSI multiplied by the number of resource blocks, its equal to $(N \times \mathrm{RSRP}) / \mathrm{RSSI}$ where $N$ is the number of resource blocks used. It indicates the quality of the received reference signal from the tower to the device.' Simultaneous measurements for RSSI and Received Signal Code Power (RSCP) were collected when the $3 \mathrm{G}$ network was in use and RSSI for the $2 \mathrm{G}$ network. They provide relevant measures of signal strength for the respective networks. RSSI, RSRP, and RSCP were recorded in $\mathrm{dBm}$ while RSRQ was measured in $\mathrm{dB}$.

Mobile phone Tx power in $\mathrm{dBm}$ were recorded across all mobile phone data technologies. Measurements were captured for the following mobile phone data technologies on the 2G network: GSM; On the 3G network: Wideband Code Division Multiple Access, High Speed Downlink Packet Access, High Speed Downlink Packet Access+, High Speed Packet Access, and High Speed Packet Access+. On the 4G network: LTE-Advanced. Wi-Fi was also measured.

\section{Statistical analysis}

Data were recorded by the Qualipoc android and stored on the handset until downloaded into a CSV file. Each recording had a separate file which was merged for the analysis. Spearman correlations were investigated between Tx power, RSSI and RSCP for the $3 \mathrm{G}$ network, and between Tx power, RSSI, RSRP, and RSRQ for the 4G network. Descriptive statistics (medians [Interquartile Ranges]) for mobile phone Tx power were determined for categorised levels of RSSI, RSRP, and RSCP for both the $3 \mathrm{G}$ and $4 \mathrm{G}$ networks. As there were only a small number of measurements recorded on the $2 \mathrm{G}$ network, correlations, and descriptive statistics were not analysed.

For $4 \mathrm{G}$ data technologies RSSI was categorised as 'excellent' $\geq-65 \mathrm{dBm}$, 'good' $<-65$ to $-75 \mathrm{dBm}$, 'fair' $<$ -75 to $-85 \mathrm{dBm}$, 'poor' $<-85$ to $-95 \mathrm{dBm}$, 'very poor' $<$ $-95 \mathrm{dBm}$. While RSRP was categorised as 'excellent' $\geq$
$-80 \mathrm{dBm}$, 'good' $<-80$ to $-90 \mathrm{dBm}$, 'fair' $<-90$ to -100 $\mathrm{dBm}$, 'poor' $<-100$ to $-110 \mathrm{dBm}$ 'very poor' $<-110$ $\mathrm{dBm}$. For $3 \mathrm{G}$ data technologies RSSI was categorised as 'excellent' $\geq-70 \mathrm{dBm}$, 'good' $<-70$ to $-85 \mathrm{dBm}$, 'fair' < -85 to $-100 \mathrm{dBm}$, 'poor' $<-100$ to $-110 \mathrm{dBm}$, 'very poor' $<-110 \mathrm{dBm}$. While RSCP was categorised as 'excellent' $\geq-60 \mathrm{dBm}$, 'good' $<-60$ to $-75 \mathrm{dBm}$, 'fair' $<$ -75 to $-85 \mathrm{dBm}$, 'poor' $<-85$ to $-95 \mathrm{dBm}$, 'very poor' $<$ $-95 \mathrm{dBm}$. These categorisations were based on the signal strength of the mobile phone for the respective networks. The time spent on each network, as well as the time spent in each category of signal strength level for the various indicators are calculated as a proportion of the total time the measurements were conducted. Time spent transmitting on each network was also calculated as a proportion of the total time the phone was transmitting. Data analysis was conducted with STATA version 13 (StataCorp, College Station, TX).

\section{Results}

Of the four participants, the mean (SD) age was 34.8 (12.4) and two were female, all worked in an urban area of greater Melbourne. Two participants were researchers, one worked as an office administrator and one as a business developer. The participants gathered between 33 and $39 \mathrm{~h}$ of data each for a combined total of $146 \mathrm{~h}$. This provided $1,445,121$ simultaneous measurements at an average of one every $364 \mathrm{~ms}$ for Tx power, RSSI, and RSRP or RSCP depending on which data technology was in use. The primary data technology in use was from the $4 \mathrm{G}$ network, with $63.9 \%$ of measurements being recorded while $4 \mathrm{G}$ technologies were active. Wi-Fi was active in $27.6 \%$ of the data recording time while the $3 \mathrm{G}$ and $2 \mathrm{G}$ networks were active 8.5 and $0.04 \%$ of the time, respectively (Fig. 1). Data technology information was missing for 400 of the $1,445,121$ simultaneous measurements.

The mobile phone was found to be transmitting a signal in $52.7 \%$ of the measurement time (761,114 measurements). When the handset was transmitting a signal the proportion of data technology usage changed. Excluding those with missing values on data technologies (67 measurements), the $4 \mathrm{G}$ network remained the primary technology in use and at a percentage of $75.2 \%$. Wi-Fi was active at less than half the time $(11.6 \%)$, while the $3 \mathrm{G}$ data technologies were used more frequently $(13.2 \%)$. Usage of $2 \mathrm{G}$ network remained rare $(0.001 \%)$.

Tables 1 and 2 show the Spearman's correlations between signal strength indicators and mobile phone $\mathrm{Tx}$ power for the $4 \mathrm{G}$ and $3 \mathrm{G}$ data technologies, respectively. For the $4 \mathrm{G}$ data technologies strong positive correlations were seen between RSSI and RSRP, with both metrics also 


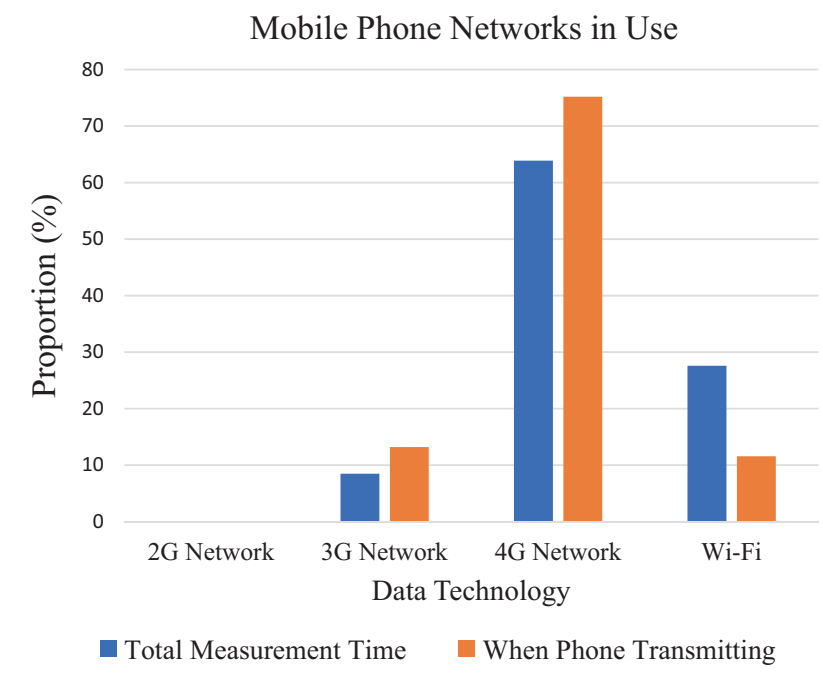

Fig. 1 Percentage of time each mobile network was active during the total data recording period compared with when the phone was transmitting

Table 1 Spearman's correlation matrix for signal strength indicators and mobile Tx power for $4 \mathrm{G}$ network data technologies

\begin{tabular}{lccc}
\hline & RSSI & RSRP & RSRQ \\
\hline RSSI & 1.00 & & \\
RSRP & $0.97^{\mathrm{a}}$ & 1.00 & \\
RSRQ & $0.22^{\mathrm{a}}$ & $0.41^{\mathrm{a}}$ & 1.00 \\
Tx power & $-0.85^{\mathrm{a}}$ & $-0.87^{\mathrm{a}}$ & $-0.37^{\mathrm{a}}$ \\
\hline
\end{tabular}

${ }^{\mathrm{a}} p$ value $<0.01$

Table 2 Spearman's correlation matrix for signal strength indicators and mobile Tx power for $3 \mathrm{G}$ network data technologies

\begin{tabular}{lcc}
\hline & RSSI & RSCP \\
\hline RSSI & 1.00 & \\
RSCP & $0.98^{\mathrm{a}}$ & 1.00 \\
Tx power & $-0.93^{\mathrm{a}}$ & $-0.93^{\mathrm{a}}$ \\
\hline
\end{tabular}

${ }^{\mathrm{a}} p$ value $<0.01$

having a strong negative correlation with Tx power. However, RSRQ did not correlate strongly with these parameters. Similarly, the results from the $3 \mathrm{G}$ network also showed a strong positive correlation between RSSI and RSCP, with both metrics showing a strong negative correlation with Tx power. Correlations between RSSI, RSCP, and $\mathrm{Tx}$ power for the $3 \mathrm{G}$ network were all stronger than the respective correlations for the $4 \mathrm{G}$ network. All correlations were found to be statistically significant.

Figures 2 and 3 show the variations in Tx power over the categorised RSSI values for $3 \mathrm{G}$ and $4 \mathrm{G}$ data technologies. Both figures showed an increase in mobile phone Tx power as the signal strength declined. The increases in Tx power for $4 \mathrm{G}$ data technologies were minimal across the 'fair',
Tx Power over RSSI for 4G Data Technologies

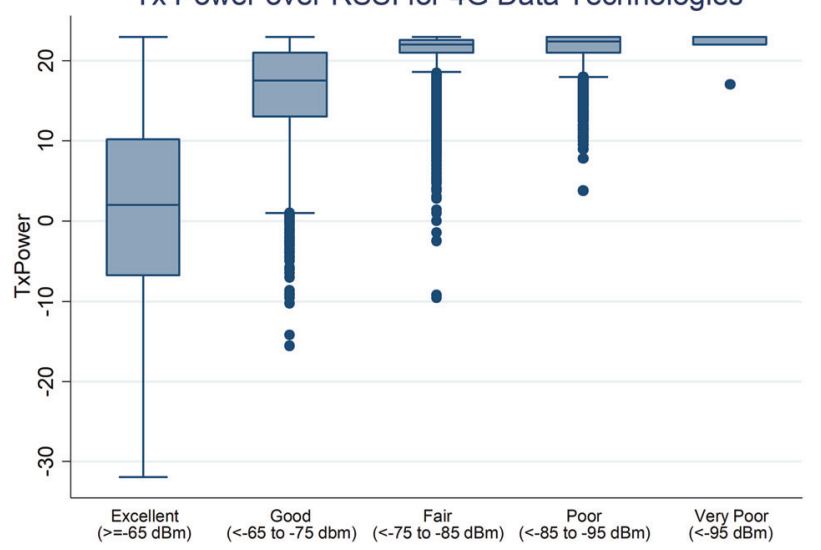

Fig. 2 Tx Power $(\mathrm{dBm})$ variations for categorised RSSI for $4 \mathrm{G}$ data technologies

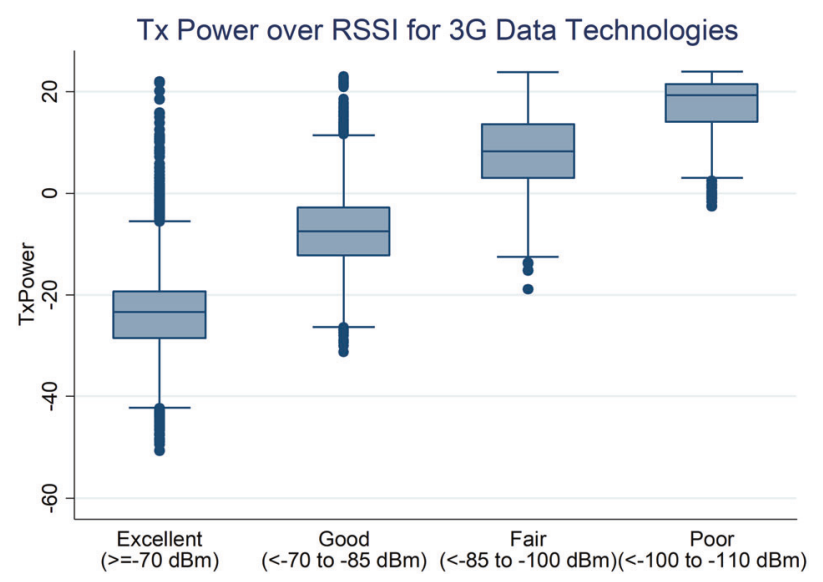

Fig. 3 Tx Power $(\mathrm{dBm})$ variations for categorised RSSI for $3 \mathrm{G}$ data technologies

'poor', and 'very poor' signal strengths, after significant increases from 'excellent' and 'good'. The increases in Tx Power across the $3 \mathrm{G}$ data technologies were more consistent across the signal strength levels. In Fig. 3, the 3G data technologies did not experience 'very poor' RSSI levels and thus no box plot is presented.

Figures 4 and 5 show the variations in Tx power over the categorised RSRP for 4G data technologies and categorised RSCP for $3 \mathrm{G}$ technologies, respectively. Similar to RSSI, mobile phone Tx power increased as RSRP and RSCP levels decreased. However, unlike RSSI in the 4G network the increases in Tx power continue to be substantial across the 'fair' and 'poor' signal strengths levels for RSRP, with a smaller increase in the 'very poor' category. While in the $3 \mathrm{G}$ network, data were recorded in the 'very poor' category for RSCP, which followed the trend of substantial increases in Tx power as signal strength declined.

Table 3 shows the summary statistics for Tx power across signal levels of RSSI, RSRP, and RSCP for the 3G and $4 \mathrm{G}$ networks which were displayed in Figs. 2-5. The 
number of measurements taken for each signal level is also reported. For the $4 \mathrm{G}$ network RSSI measurement only 93 measurements were recorded for the 'very poor' signal level category. The proportion of recorded measurements for

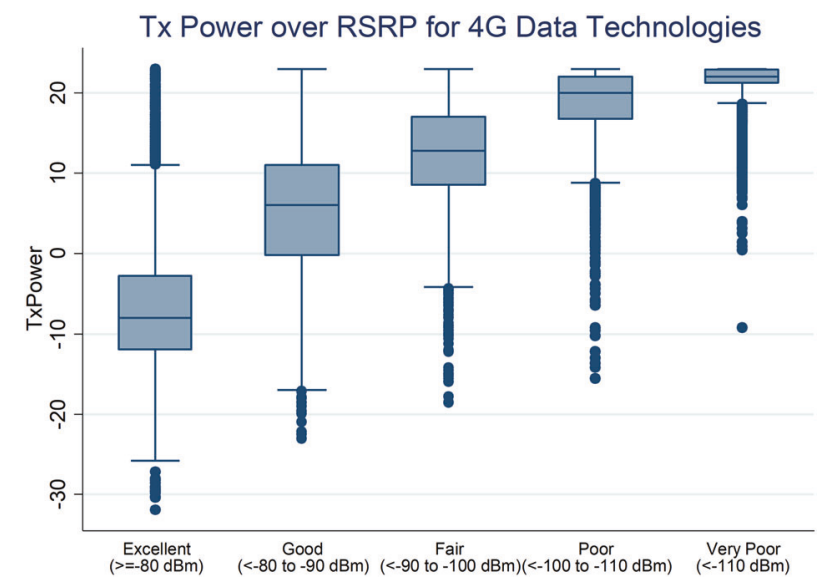

Fig. 4 Tx Power $(\mathrm{dBm})$ variations for categorised RSRP for $4 \mathrm{G}$ data technologies

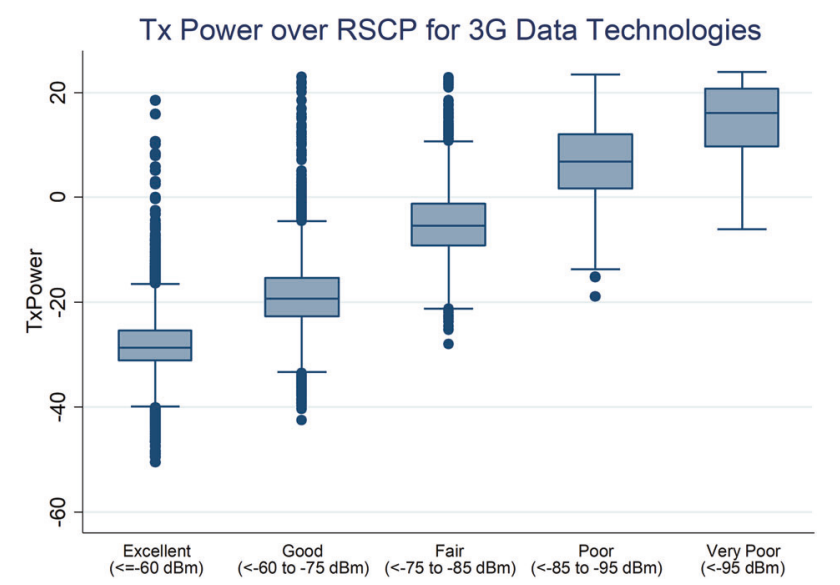

Fig. 5 Tx Power $(\mathrm{dBm})$ variations for categorised RSCP for $3 \mathrm{G}$ data technologies

Table 3 Median and interquartile ranges for $\mathrm{Tx}$ power $(\mathrm{dBm})$ for received signal strength indicators on the $3 \mathrm{G}$ and $4 \mathrm{G}$ networks
RSSI was similar between the $3 \mathrm{G}$ and $4 \mathrm{G}$ networks. These measurements were predominantly recorded in areas of 'fair' signal strength level or better, with only 11 and $8.01 \%$ of measurements being recorded in the 'poor' or 'very poor' signal strength levels. The proportions of recorded measurements were also similar between RSCP and RSRP, with the exception of good signal level were $3 \mathrm{G}$ RSCP recorded $28 \%$ of measurements at the level compared with 4G RSRP with $14 \%$. RSCP and RSRP differed from RSSI as a greater proportion of measurements were recorded in the 'poor' and 'very poor' signal levels (RSCP 43\% RSRP 50\%) and were much lower in the 'excellent' category as shown in Fig. 6.

\section{Discussion}

This study investigated correlations between multiple signal strength indicators and mobile phone Tx power as measured by the Qualipoc Handheld Android across the 3G and 4G networks. It also assessed variations in $\mathrm{Tx}$ power via descriptive statistics for categorised RSSI, RSRP, and RSCP. The mobile phone to be transmitting $52.7 \%$ of the time measurements were recorded, however this does not necessarily indicate that the participants were actively using

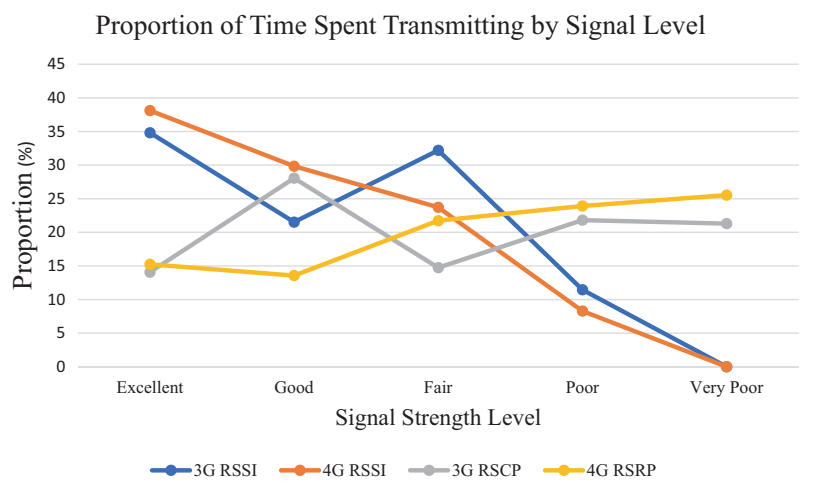

Fig. 6 Proportion of recorded measurements by signal level 
the mobile devices for that entire period as mobile apps can be updating and running in the background. We found strong negative correlations between the signal strength indicators and Tx power for both $3 \mathrm{G}$ and $4 \mathrm{G}$ data technologies. This was reflected in the significant increases in handset Tx power as categorised signal strength levels weakened. Strong positive correlations were also observed between RSSI and RSRP for the 4G network, and between RSSI and RSCP for the 3G network. However, in the $4 \mathrm{G}$ network RSRQ only moderately correlated with RSSI and RSRP. The $4 \mathrm{G}$ network was the predominant network in use and the phones were generally operating in areas with 'fair' or better signal strength during the data recording periods. The maximum recorded Tx power was $23 \mathrm{dBm}$ $(200 \mathrm{~mW})$.

Previous research has shown considerable variation in the output power of a mobile phone in different developed environments, with rural areas having on average a higher output power level than urban environments [16-18, 22]. It has been suggested that the lower concentration of base stations in rural environments and therefore the greater distance to a base station, resulted in subsequent poorer signal levels which were responsible for the higher output power levels. Furthermore, living in an urban/rural environment should be considered for RF-EMF exposure classification in future epidemiology studies [17], as RF-EMF exposure from mobile phones is directly proportional to the transmitted power.

However, this study shows there to be significant variation even within the urban environment of greater Melbourne, with Tx power several times higher when the signal strength level is 'poor' and 'very poor' compared with 'excellent'. This is an important factor to consider in epidemiological studies as Tx power is the main contributor to mobile phone RF-EMF exposure. It also shows that a person who makes fewer mobile phone calls, but does so in an area with poor signal strength will have higher RF-EMF exposure compared with someone who makes more calls but in good areas of signal strength.

Although the higher concentrations of base stations in an urban environment and consequently the shorter average distances between receiver and transmitter are considerable factors, research has shown $\mathrm{Tx}-\mathrm{Rx}$ distance to only moderately correlate with RSRP on the 4G network (LTE) [30]. Other important factors are line of sight, vegetation, reflective walls, and building materials between the base station and mobile phone user [23]. In addition, base station factors such as antenna height, direction, and frequency are also important in determining the electric field strength [31]. A combination of these factors is the likely cause for the wide range of signal strength and Tx power levels seen in this study.
The strong negative correlations and significant increases in Tx power found with signal strength level within an urban environment show a potentially substantial source of measurement error uncertainty that has not previously been controlled for in epidemiological studies. Various sources of uncertainty have already been identified in RFEMF exposure assessment for both near and far-field sources [15].

Yet the significant increases found in this study require further consideration as handsets account for the majority of RF-EMF exposure to the brain and body [3], and are frequently used as an exposure proxy. It is also important to consider that in urban environments where the concentration of base stations is higher that far-field RF-EMF exposure would also be higher. Previous far-field RF-EMF exposure assessment research in Melbourne found the highest mean exposure to be in the central business district $(0.89 \mathrm{~V} / \mathrm{m})$ and the lowest in a suburban residential area $(0.05 \mathrm{~V} / \mathrm{m})$ [32]. Therefore, there may be a trade off in reducing sporadic near-field exposure from mobile phones but increasing lower and constant far-field exposure from base stations. This presents another factor that may need to be considered in total RF-EMF exposure assessment.

\section{Strengths and limitations}

This study has a number of strengths. The simultaneous and objective measurements by the Qualipoc handheld android directly from the chipset are worth mentioning. These data were collected on multiple signal strength indicators for both $3 \mathrm{G}$ and $4 \mathrm{G}$ networks with Tx power, which will aid in estimating personnel RF-EMF exposure. In addition, the relatively fast-sampling speed, and the comprehensive assessment of data technologies across $3 \mathrm{G}$ and $4 \mathrm{G}$ networks are further strengths of the study.

However, the study also had some limitations. The use of one model (Sony Xperia XZ) of mobile phone is limiting as different phone models can have different SAR limits, and different locations for antennae that could vary RF-EMF exposure [15]. Despite, all mobile phone models operating within the SAR safety limits other handsets may be more efficient and use less Tx power at poorer signal levels. Further limitations include data collection only taking place in greater Melbourne area and not in rural areas, and only in standard working hours. Data were not collected on the distance the mobile phone was away from the body or head when transmitting limiting RF-EMF exposure estimates. Although the small number of participants is a limitation it is somewhat offset by the large number of measurements taken. It is suspected that potential participants were reluctant to use a mobile phone other than their own which contributed to the small number of participants. 
Despite these limitations, this study has shown RF-EMF exposure from mobile phones to vary significantly with signal strength level, with exposure differing by orders of magnitude between poor and excellent signal strength levels on the $3 \mathrm{G}$ and $4 \mathrm{G}$ networks. This exposure uncertainty has probably introduced non-differential exposure misclassification in many previous epidemiological studies confined to similar geographical areas. However, in studies which have participants in diverse geographical locations and developed environments this misclassification may have been differential. Although data were only collected in greater Melbourne, it is believed that the correlations observed between the signal strength indicators and $\mathrm{Tx}$ power would be generalisable to mobile phone users in other environments. However, it is likely in rural and suburban environments that average Tx power would be higher as average signal strength is likely to be poorer due to the lower concentration of base stations. To prevent exposure misclassification, it is recommended future epidemiological studies gather data on factors that influence mobile phone signal strength. These factors include distance from base station, line of site, vegetation, building materials, and service provider. Service providers with poorer coverage would result in weaker reception and increased exposure. This information combined with mobile phone usage and the distance the phone is held from the head and body when in use is important for accurate RF-EMF exposure assessment.

\section{Conclusions}

This study has demonstrated the use of the Qualipoc handheld android phone to assess the correlations between multiple signal strength indicators and Tx power on the $3 \mathrm{G}$ and $4 \mathrm{G}$ networks in the greater Melbourne area. The phones provided objective measurements of exposure rather than self-reported estimates from surveys. It found Tx power from a mobile phone device varied greatly depending on signal strength level, with exposure differing by orders of magnitude between poor and excellent signal strength levels. In order to reduce measurement error in RF-EMF exposure, data on distance the phone is held from the body and Tx power are required. As Tx power is difficult to measure and costly with the Qualipoc android device, it is recommended that future epidemiological studies control for signal strength as a proxy due to the strong correlations found between signal strength and $\mathrm{Tx}$ power. Factors influencing signal strength, such as distance from base station or base station concentration, line of site, vegetation, building materials, and service provider provide measures to control for signal strength.

\section{Data availability}

Please contact author for data requests. The data sharing should follow Monash University data sharing protocol.

Acknowledgements The study was funded by the National Health and Medical Research Council, Australia (grant number APP 545927).

\section{Compliance with ethical standards}

Conflict of interest Michael Abramson owns a small parcel of shares in Telstra, which operates a mobile telephone network in Australia. The other authors declare that they have no conflicts of interest.

Publisher's note Springer Nature remains neutral with regard to jurisdictional claims in published maps and institutional affiliations.

Open Access This article is licensed under a Creative Commons Attribution 4.0 International License, which permits use, sharing, adaptation, distribution and reproduction in any medium or format, as long as you give appropriate credit to the original author(s) and the source, provide a link to the Creative Commons license, and indicate if changes were made. The images or other third party material in this article are included in the article's Creative Commons license, unless indicated otherwise in a credit line to the material. If material is not included in the article's Creative Commons license and your intended use is not permitted by statutory regulation or exceeds the permitted use, you will need to obtain permission directly from the copyright holder. To view a copy of this license, visit http://creativecommons. org/licenses/by/4.0/.

\section{References}

1. Ahlbom A, Bridges J, de Seze R, Hillert L, Juutilainen J, Mattsson MO, et al. Possible effects of electromagnetic fields (EMF) on human health-opinion of the scientific committee on emerging and newly identified health risks (SCENIHR). Toxicology. 2008;246:248-50.

2. van Deventer E, van Rongen E, Saunders R. WHO research agenda for radiofrequency fields. Bioelectromagnetics. 2011;32:417-21.

3. Roser K, Schoeni A, Burgi A, Roosli M. Development of an RFEMF exposure surrogate for epidemiologic research. Int J Environ Res Public Health. 2015;12:5634-56.

4. Abramson MJ, Benke GP, Dimitriadis C, Inyang IO, Sim MR, Wolfe RS, et al. Mobile telephone use is associated with changes in cognitive function in young adolescents. Bioelectromagnetics. 2009;30:678-86.

5. Bhatt CR, Benke G, Smith CL, Redmayne M, Dimitriadis C, Dalecki A, et al. Use of mobile and cordless phones and change in cognitive function: a prospective cohort analysis of Australian primary school children. Environ Health. 2017;16:62.

6. Redmayne M, Smith CL, Benke G, Croft RJ, Dalecki A, Dimitriadis $\mathrm{C}$, et al. Use of mobile and cordless phones and cognition in Australian primary school children: a prospective cohort study. Environ Health. 2016;15:26.

7. Roser K, Schoeni A, Roosli M. Mobile phone use, behavioural problems and concentration capacity in adolescents: a prospective study. Int J Hyg Environ Health. 2016;219:759-69.

8. Sadetzki S, Langer CE, Bruchim R, Kundi M, Merletti F, Vermeulen $\mathrm{R}$, et al. The MOBI-Kids study protocol: challenges in 
assessing childhood and adolescent exposure to electromagnetic fields from wireless telecommunication technologies and possible association with brain tumor risk. Front Public Health. 2014;2:124

9. Schoeni A, Roser K, Roosli M. Memory performance, wireless communication and exposure to radiofrequency electromagnetic fields: a prospective cohort study in adolescents. Environ Int. 2015;85:343-51.

10. Thomas S, Benke G, Dimitriadis C, Inyang I, Sim MR, Wolfe R, et al. Use of mobile phones and changes in cognitive function in adolescents. Occup Environ Med. 2010;67:861-6.

11. Cardis E, Deltour I, Vrijheid M, Combalot E, Moissonnier M, Tardy $\mathrm{H}$, et al. Brain tumour risk in relation to mobile telephone use: results of the INTERPHONE international case-control study. Int J Epidemiol. 2010;39:675-94.

12. Goedhart G, Kromhout H, Wiart J, Vermeulen R. Validating selfreported mobile phone use in adults using a newly developed smartphone application. Occup Environ Med. 2015;72:812-8.

13. Inyang I, Benke G, Morrissey J, McKenzie R, Abramson M. How well do adolescents recall use of mobile telephones? Results of a validation study. BMC Med Res Methodol. 2009;9:36.

14. Vrijheid M, Cardis E, Armstrong BK, Auvinen A, Berg G, Blaasaas KG, et al. Validation of short term recall of mobile phone use for the Interphone study. Occup Environ Med. 2006;63:237-43.

15. Brzozek C, Benke KK, Zeleke BM, Abramson MJ, Benke G. Radiofrequency electromagnetic radiation and memory performance: sources of uncertainty in epidemiological cohort studies. Int J Environ Res Public Health. 2018;15: pii: E592. https://doi. org/10.3390/ijerph15040592

16. Lönn S, Forssén U, Vecchia P, Ahlbom A, Feychting M. Output power levels from mobile phones in different geographical areas; implications for exposure assessment. Occup Environ Med. 2004;61:769-72.

17. Hillert L, Ahlbom A, Neasham D, Feychting M, Järup L, Navin R, et al. Call-related factors influencing output power from mobile phones. J Expo Sci Environ Epidemiol. 2006;16:507.

18. Persson T, Törnevik C, Larsson LE, Lovén J. Output power distributions of terminals in a $3 \mathrm{G}$ mobile communication network. Bioelectromagnetics. 2012;33:320-5.

19. Gati A, Conil E, Wong M-F, Wiart J. Duality between uplink local and downlink whole-body exposures in operating networks. IEEE Trans Electromagn Compat. 2010;52:829-36.

20. Gati A, Hadjem A, Wong M-F, Wiart J. Exposure induced by WCDMA mobiles phones in operating networks. IEEE Trans Wirel Commun. 2009;8:5723-7.

21. Joshi P, Agrawal M, Thors B, Colombi D, Kumar A, Törnevik C. Power level distributions of radio base station equipment and user devices in a $3 \mathrm{G}$ mobile communication network in India and the impact on assessments of realistic RF EMF exposure. IEEE Access. 2015;3:1051-9.

22. Joshi P, Colombi D, Thors B, Larsson L-E, Törnevik C. Output power levels of $4 \mathrm{G}$ user equipment and implications on realistic RF EMF exposure assessments. IEEE Access. 2017;5:4545-50.

23. Beekhuizen J, Vermeulen R, van Eijsden M, van Strien R, Burgi A, Loomans E, et al. Modelling indoor electromagnetic fields (EMF) from mobile phone base stations for epidemiological studies. Environ Int. 2014;67:22-6.

24. Bhatt CR, Redmayne M, Abramson MJ, Benke G. Instruments to assess and measure personal and environmental radiofrequencyelectromagnetic field exposures. Australas Phys Eng Sci Med. 2016;39:29-42.

25. Lauridsen M, Rodriguez I, Mikkelsen LM, Gimenez LC, Mogensen $\mathrm{P}$, eds. Verification of $3 \mathrm{G}$ and $4 \mathrm{G}$ received power measurements in a crowdsourcing Android app. 2016 IEEE Wireless Communications and Networking Conference; Doha, Qatar: IEEE; 2016. https://doi.org/10.1109/WCNC.2016. 7564930

26. Enami R, Shi Y, Rajan D, Camp J. Pre-crowdsourcing: predicting wireless propagation with phone-based channel quality measurements. Comput Commun. 2018;132:96-110.

27. Lauridsen M, Kolding T, Pocovi G, Mogensen P, eds. Reducing handover outage for autonomous vehicles with LTE hybrid access. 2018 IEEE International Conference on Communications (ICC); Kansas City, MO, USA: IEEE; 2018. https://doi.org/10. 1109/ICC.2018.8422737

28. Alvarez A, Díaz A, Merino P, Rivas FJ eds. Field measurements of mobile services with Android smartphones. 2012 IEEE Consumer Communications and Networking Conference (CCNC); Las Vegas, NV, USA: IEEE: 2012.

29. Welch K. Evolving cellular technologies for safer drone operation. Qualcomm, San Diego, CA, USA: Qualcomm 5G White Paper and Presentations, Tech Rep; 2016.

30. Simpson O, Sun Y. LTE RSRP, RSRQ, RSSNR and local topography profile data for RF propagation planning and network optimization in an urban propagation environment. Data Brief. 2018;21:1724-37.

31. Beekhuizen J, Kromhout H, Burgi A, Huss A, Vermeulen R. What input data are needed to accurately model electromagnetic fields from mobile phone base stations? J Expo Sci Environ Epidemiol. 2015;25:53-7.

32. Thielens A, Van den Bossche M, Brzozek C, Bhatt CR, Abramson MJ, Benke G, et al. Representativeness and repeatability of microenvironmental personal and head exposures to radio-frequency electromagnetic fields. Environ Res. 2018;162:81-96. 


\section{University Library}

\section{- M I I N E R VA \\ A gateway to Melbourne's research publications}

Minerva Access is the Institutional Repository of The University of Melbourne

Author/s:

Brzozek, C;Zeleke, BM;Abramson, MJ;Benke, KK;Benke, G

Title:

Radiofrequency electromagnetic field exposure assessment: a pilot study on mobile phone signal strength and transmitted power levels

Date:

2021-02-01

\section{Citation:}

Brzozek, C., Zeleke, B. M., Abramson, M. J., Benke, K. K. \& Benke, G. (2021).

Radiofrequency electromagnetic field exposure assessment: a pilot study on mobile phone signal strength and transmitted power levels. Journal of Exposure Science and

Environmental Epidemiology, 31 (1), pp.62-69. https://doi.org/10.1038/s41370-019-0178-6.

Persistent Link:

http://hdl.handle.net/11343/251949

License:

cc-by 